Volume 5 Nomor. 1, April 2020

P -ISSN : 2541-1179, E-ISSN : 2581-1711

Ojs :http://journal.uin-alauddin.ac.id/index.php/instek/index

Email : instek@uin-alauddin.ac.id

\title{
PEMANFAATAN KODE QR PADA PENINGKATAN PELAYANAN DAN KEPUASAN PELANGGAN PADA RESTORAN
}

\author{
FAISAL ${ }^{1}$, MUHAMMAD AZMI FAUZAN ANAS ${ }^{2}$ \\ Jurusan Teknik Informatika UIN Alauddin Makassar ${ }^{1,2}$ \\ Email : ${ }^{1)}$ faisal.rahman@uin-alauddin.ac.id ${ }^{2}$ azmifauzan@gmail.com
}

\begin{abstract}
ABSTRAK
Kode QR merupakan sebuah system yang menggunkan kode gambar dua deimensi yang juga berasal dari evolusi Barcode. Penggunaan kode QR sudah sangat lazim di berbagai negara. Hal ini dikarenakan kemampuannya menyimpan data yang lebih besat daripada barcode sehingga mampu mengkodekan informasi dalam berbagai macam Bahasa. Kode QR menggunakan suatu jenis kode matriks atau kode dalam bentuk dua dimensi yang dikembangkan oleh Denso Wave.

Dalam penelitian ini, jenis penelitian yang digunakan adalah penelitian deskriptif kualitatif adapun metode kualitatif. Adapun metode perancangannya menggunakan unified modelling languange (UML). Analisis yang dilakukan mencakup analisis sistem yang berjalan dan analisis sistem yang diusulkan,

Hasil penelitian ini berupa aplikasi berbasis android yang dapat memudahkan system pemesanan dan pelayanan pada restoran dengan menggunkan bantuan teknologi kode QR.
\end{abstract}

Kata Kunci : QR code, Android, Reservasi

\section{PENDAHULUAN}

Salah satu unsur yang penting dan perlu mendapat perhatian dalam dunia usaha adalah keberadaan konsumen. Konsumen merupakan pemakai barang atau jasa yang tersedia. Para konsumen pasti akan mencari produk-produk barang atau jasa sesuai dengan kebutuhannya, sehingga dapat memuaskan dirinya.

Salah satu dunia usaha yang bersentuhan langsung dengan konsumen adalah restoran atau rumah makan. Restoran adalah unit usaha yang inti bisnisnya yakni menjual makanan dan minuman kepada konsumen individu maupun kelompok, dimana didalamnya dipekerjakan beberapa pegawai atau karyawan.

Pada beberapa restoran terdapat suatu masalah yang sering terjadi, diantaranya karyawan restoran keliru dalam mengantar pesanan, karyawan jarang 
Volume 5 Nomor. 1, April 2020

P -ISSN : 2541-1179, E-ISSN : 2581-1711

Ojs :http://journal.uin-alauddin.ac.id/index.php/instek/index

Email : instek@uin-alauddin.ac.id

menawarkan teh ataupun kopi pada saat sarapan pagi, karyawan tidak cekatan, serta karyawan yang kurang ramah. Disisi lain tamu merasa tidak mendapatkan layanan dengan baik, tamu merasa tidak nyaman dan bosan pada saat menuggu hidangan yang terlalu lama disajikan, tamu merasa tidak puas dengan pelayanan yang diberikan karena kurangnya inovasi dalam meningkatkan pelayanan direstoran tersebut.

Maka dari itu muncullah solusi atau ide yang dapat memudahkan restoran dalam bentuk pemesanan makanan dengan pemanfaatan dan bantuan teknologi kode QR yang terhubung langsung dengan android, sehingga pemesanan makanan dilakukan dengan cara mengaktifkan aplikasi restoran dan melakukan pemesanan makanan dengan bantuan sistem scan QR kode yang telah disediakan di setiap meja dan menambahkan fitur estimasi waktu pemesanan makanan, sehingga konsumen dapat melihat estimasi waktu ketika telah memesan makanan pada restorant tersebut. Kode QR atau Quick Response Code merupakan gambar dua dimensi yang memiliki kemampuan untuk menyimpan data. Adapun fungsinya untuk menyimpan data berupa teks, baik numerik, alfanumerik, maupun kode biner yang merupakan bagian dari kode tersebut.

\section{METODE PENELITIAN}

Dalam penelitian ini menggunakan jenis penelitian kualitatif dimana penelitian ini menjelaskan tentang riset yang bersifat deskriptif dan cenderung menggunakan analisis proses dan makna lebih ditonjolkan dalam metode kualitatif. Adapun lokasi penelitian adalah restoran "Grind \& Pull” yang beralamat di Jl. A. Mappanyukki No.40, Makassar.

Penelitian ini menggunakan metode pendekatan penelitian saintifik yaitu pendekatan penelitian berdasarkan ilmu pengetahuan dan teknologi. Adapun beberapa instrument penelitian yang digunakan dalam penelitian yaitu :

a. Perangkat Keras, yang terdiri atas : Laptop Asus Strix G Ram 8GB, Smartphone Vivo V7 plus, Harddisk 1 TB. dan Flashdisk 16 GB. 
Volume 5 Nomor. 1, April 2020

P -ISSN : 2541-1179, E-ISSN : 2581-1711

Ojs :http://journal.uin-alauddin.ac.id/index.php/instek/index Email : instek@uin-alauddin.ac.id

b. Perangkat Lunak, yang meliputi : Android Studio, Adobe XD (Design), Microsoft Office, Microsoft Visio, dan Windows 10 Pro 64-bit.

\section{HASIL DAN PEMBAHASAN}

Analisis sistem merupakan penguraian dari suatu sistem yang utuh ke dalam bagian-bagian komponennya untuk mengidentifikasi dan mengevaluasi permasalahan.

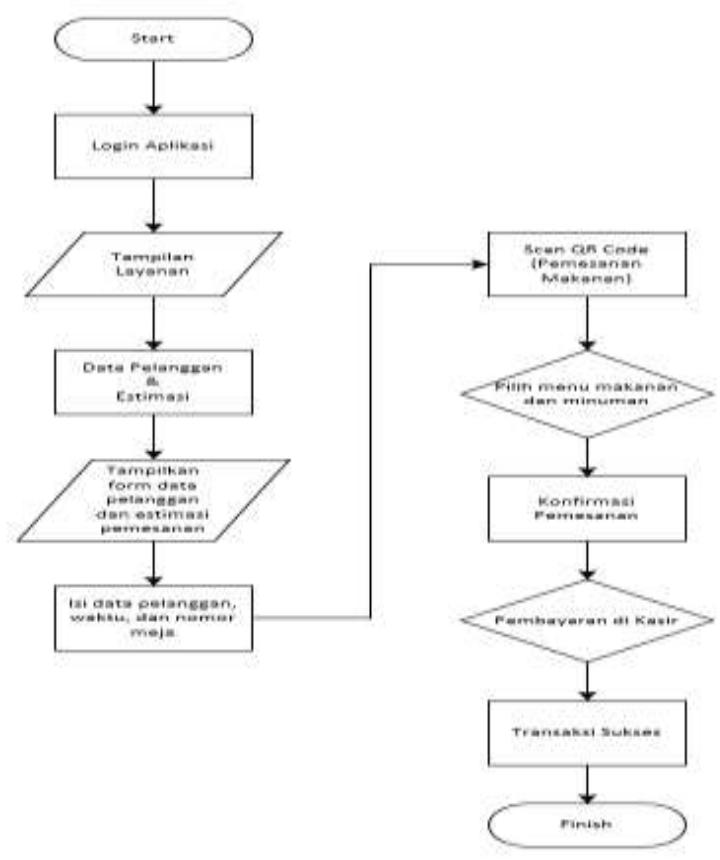

Gambar 1. Flowchart analisis sistem yang diusulkan

Pada gambar 1 dimana sebuah proses sistem pelayanan yang diusulkan. Sistem pelayanan yang diusulkan berupa pelayanan menggunakan bantuan apliksi yang terhubung dengan sistem kode QR. Sistem ini berawal dari calon konsumen yang ingin memesan, terlebih dahulu menggunakan aplikasi restoran tersebut untuk di hubungkan ke kode QR yang telah disediakan pada setiap meja restoran tersebut. Pada tahap awal, konsumen membuka aplikasi dan masuk ke menu login. Jika sudah login, konsumen tersebut akan langsung masuk ke halaman selanjutnya. Setelah berhasil melakukan login, akan tampil menu jenis pelayanan, yang terdiri dari pemesananan makanan melalui scan kode QR dan penginputan nomor meja melalui menu data pelanggan dengan estimasi waktu pemesanan. 
Volume 5 Nomor. 1, April 2020

P -ISSN : 2541-1179, E-ISSN : 2581-1711

Ojs :http://journal.uin-alauddin.ac.id/index.php/instek/index

Email : instek@uin-alauddin.ac.id

\section{Analisis Masalah}

Dari hasil pengamatan, diketahui bahwa perlu adanya peningkatan pelayanan pada restoran, dikarenakan jumlah konsumen terhadap beberapa restoran semakin meningkat dan membutuhkan pelayanan yang maksimal. Dengan adanya peningkatan tersebut, akan ada banyak masalah yang teratasi, seperti antrian dalam pemesanan, pesanan yang tidak sesuai, tempat meja yang disediakan penuh dan lain hal sebagainya. Dengan demikian yang akan terjadi selanjutnya mengurangi keluhan-keluhan dari para konsumen. Sehingga para konsumen dapat menikmati makanan yang di hidangkan oleh restoran tersebut.

\section{Analisis Kebutuhan Sistem}

\section{a. Analisis Kebutuhan Non Fungsional}

Kebutuhan non fungsional menggambarkan kebutuhan sistem yang menitik beratkan pada perilaku yang dimiliki oleh konsumen. Kebutuhan yang dianalisis antara lain perangkat lunak, perangkat keras, serta user sebagai bahan analisis kekurangan dan kebutuhan yang harus dipenuhi dalam perancangan system yang akan diterapkan.

1) Analisis Perangkat Lunak (Software)

Perangkat lunak digunakan dalam sebuah system yang merupakan sebuah himpunan perangkat yang mendukung atau dibutuhkan untuk membuat aplikasi pelayanan restoran untuk memudahkan pelanggan dalam pemesanan.

2) Analisis Perangkat Keras

Computer/handphone dan webcame adalah sebuah perangkat keras yang tidak luput dari perangkat lunak sebagai interaksinya. Perangkat lunak memberikan sebuah perintah-perintah terhadap perangkat keras agar edukasi ini menggunakan perangkat keras sebagai pendukungnya. 
Volume 5 Nomor. 1, April 2020

P -ISSN : 2541-1179, E-ISSN : 2581-1711

Ojs :http://journal.uin-alauddin.ac.id/index.php/instek/index

Email : instek@uin-alauddin.ac.id

\section{b. Analisis Kebutuhan Fungsional}

Kebutuhan fungsional berhubungan dengan fitur software yang akan dibuat atau dikembangkan. Berikut ini adalah tahapan analisis kebutuhan fungsional aplikasi game edukasi ini. Analisis yang akan dilakukan dimodelkan dengan menggunakan UML (Unified Modeling Language). Tahap pemodelan dalam analisis tersebut antara lain.

\section{1) Use Case Diagram}

Use Case Diagram merupakan gambaran scenario dari interaksi antara pengguna dengan system. use case diagram menggambarkan hubungan antara actor dan kegiatan yang dapat dilakukannya terhadap aplikasi.

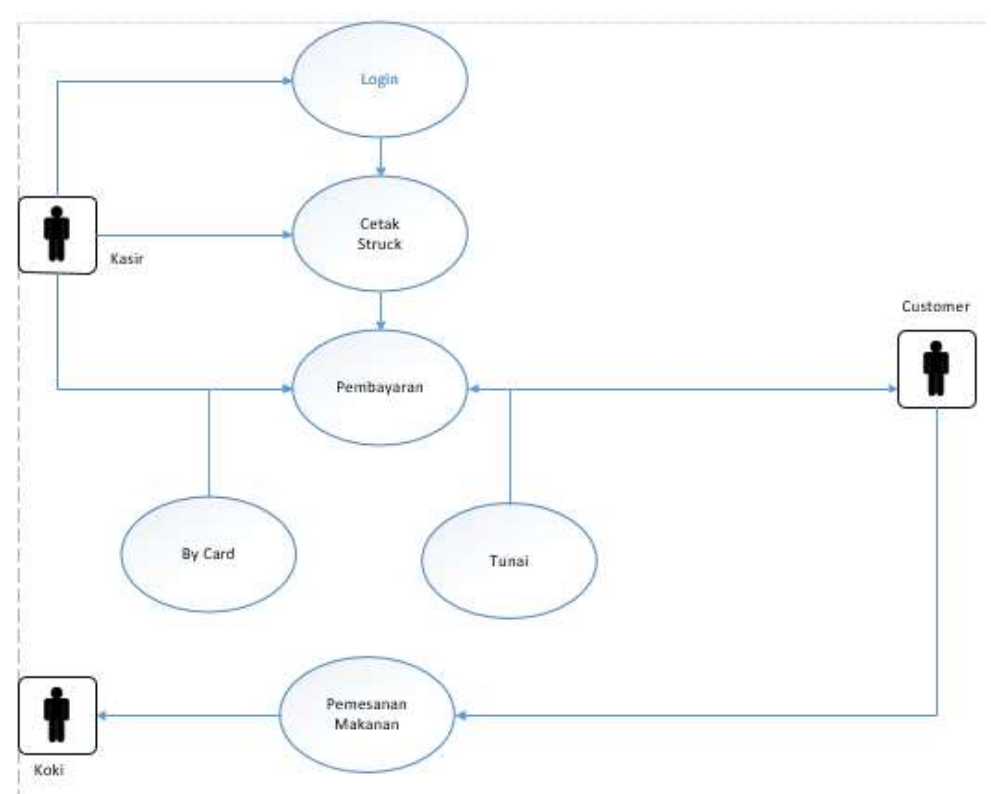

Gambar 2. Use Case Diagram

Pada gambar 2. diatas menjelaskan tentang hal-hal yang dilakukan oleh konsumen dan pelayan restoran seperti memulai aplikasi, login user, login kasir, memesan makanan dan melakukan pembayaran. 
Volume 5 Nomor. 1, April 2020

P -ISSN : 2541-1179, E-ISSN : 2581-1711

Ojs :http://journal.uin-alauddin.ac.id/index.php/instek/index

Email : instek@uin-alauddin.ac.id

2) Sequence Diagram

Sequence diagram merupakan sebuah diagram yang menggambarkan interaksi masing-masing objek pada setiap use case dalam urusan waktu. Interaksi ini berupa pengiriman serangkaian data antar objek-objek yang saling berinteraksi.

\section{c. Desain Sistem}

Pada proses perancangan desain aplikasi, dalam hal ini desain tampilan perlu adanya sketsa yang digunakan untuk menggambarkan pembuatan media. Sketsa tersebut dibentuk dalam sebuah flowchart. Flowchart adalah penggambaran secara grafik dari langkah-langkah dan urutan-urutan prosedur dari suatu aplikasi agar pembuatan program aplikasi dilakukan secara terurut. Berikut salah satu dari beberapa flowchart desain sistem yang dibua, yaitu flowchart pada menu utama.

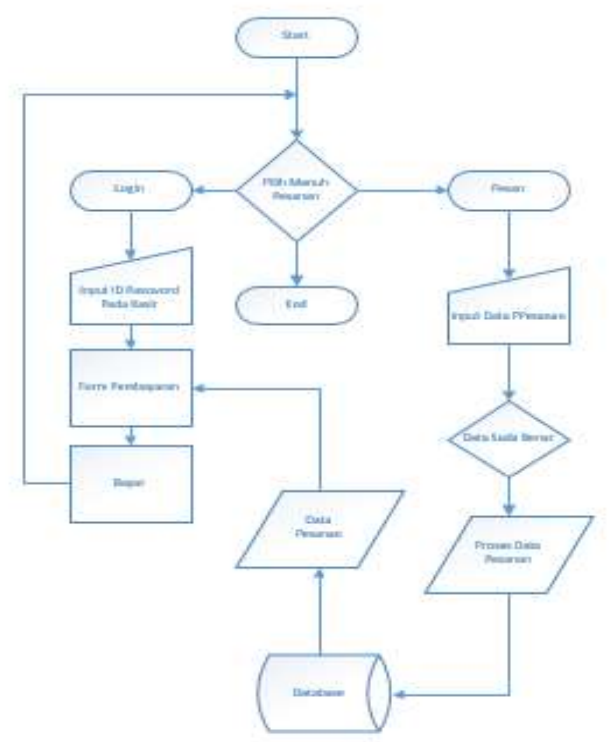

Gambar 3. Flowchart Pada Menu Utama

Adapun hasil dari implementasi sistem yang telah dibuat yaitu sebagai berikut :

1. Splash screen

Pada halaman awal aplikasi, terdapat gambar berupa logo dan nama aplikasi ketika membuka aplikasi. Splash screen berfungsi sebagai 
Volume 5 Nomor. 1, April 2020

P -ISSN : 2541-1179, E-ISSN : 2581-1711

Ojs :http://journal.uin-alauddin.ac.id/index.php/instek/index Email : instek@uin-alauddin.ac.id

tampilan awal dari sebuah aplikasi yang berfungsi untuk memperkenalkan logo dari aplikasi tersebut.

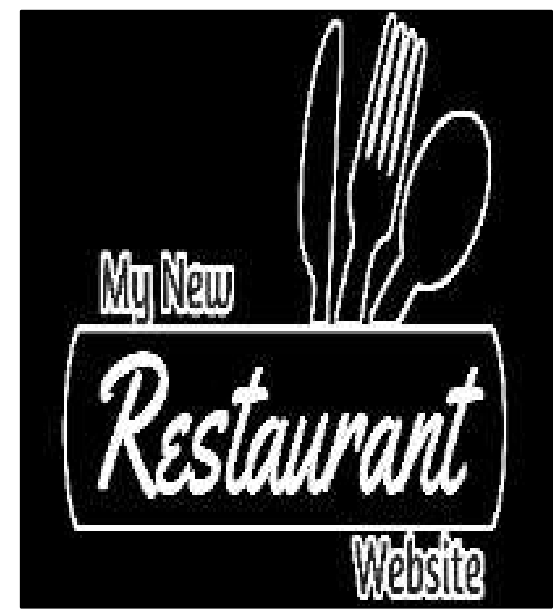

Gambar 4. Menu Splash Screen

2. Antarmuka login

Halaman ini merupakan halaman untuk pengimputan nama user dan password. Jike belum terdaftar maka user harus memilih tombol "sign up" atau "buat akun". Jika sudah memiliki akun, pengguna tinggal menekan tombol "sign in" kemudian akan masuk ke halaman berikutnya

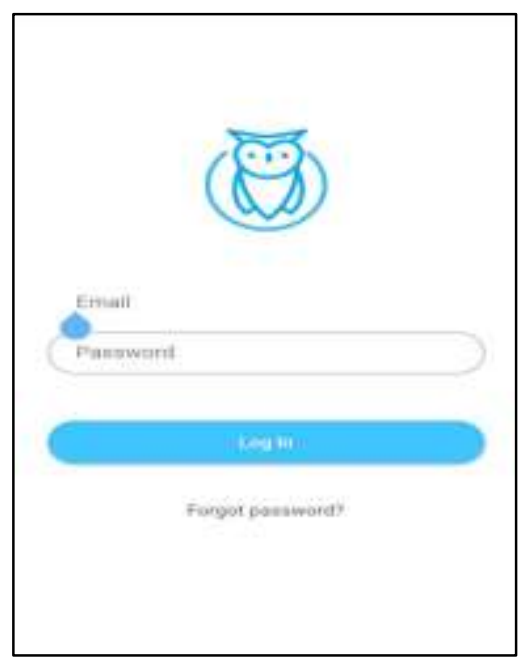

Gambar 5. Menu Login 
Volume 5 Nomor. 1, April 2020

P -ISSN : 2541-1179, E-ISSN : 2581-1711

Ojs :http://journal.uin-alauddin.ac.id/index.php/instek/index Email : instek@uin-alauddin.ac.id

3. Antarmuka pilih layanan

Pada halaman ini terdapat 2 pilihan layanan, diantaranya tombol "scan $Q R$ code”. Dimana pengguna akan diarahkan untuk melakukan scan kode QR yang telah disediakan di setiap meja pada restoran tersebut agar dapat memasuki halaman daftar menu makanan maupun minuman. Dan tombol "reservasi" yang digunakan untuk memesan meja dan memantau estimasi waktu konsumen yang sedang berada di restoran tersebut.

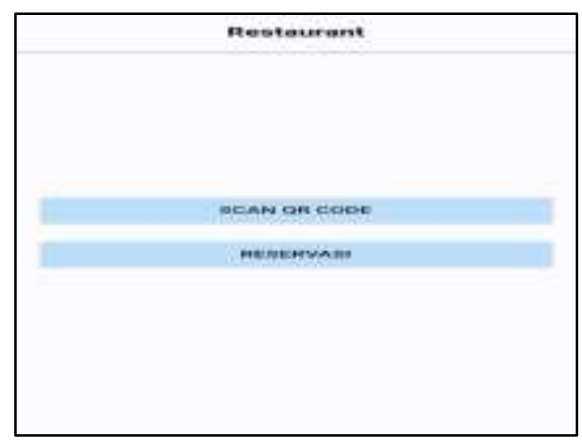

Gambar 6. Menu Pilih Layanan

4. Antarmuka pemesanan makanan (scan QR Code dan daftar menu)

Pada halaman ini akan tertampil daftar-daftar menu makanan dan minuman yang di dalamnya terbagi menjadi 2 jenis menu yaitu menu makanan biasa dan menu makanan populer.
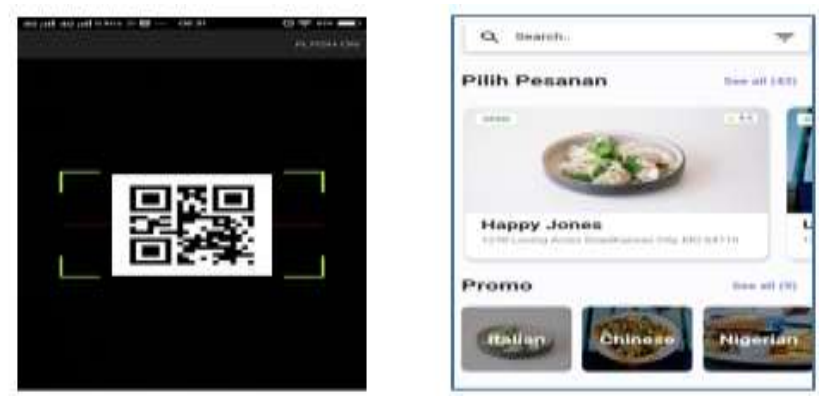

Gambar 7. Scan QR Code \& Menu Pemesanan Makanan

5. Antarmuka data pelanggan dan estimasi waktu

Pada halaman ini terbagi lagi menjadi 2 halaman yaitu halaman estimasi waktu untuk memperkirakan lama waktu konsumen dari awal 
Volume 5 Nomor. 1, April 2020

P -ISSN : 2541-1179, E-ISSN : 2581-1711

Ojs :http://journal.uin-alauddin.ac.id/index.php/instek/index Email : instek@uin-alauddin.ac.id

pemesanan makanan hingga proses pembayaran dan halaman data pelanggan untuk menginput nomor meja.
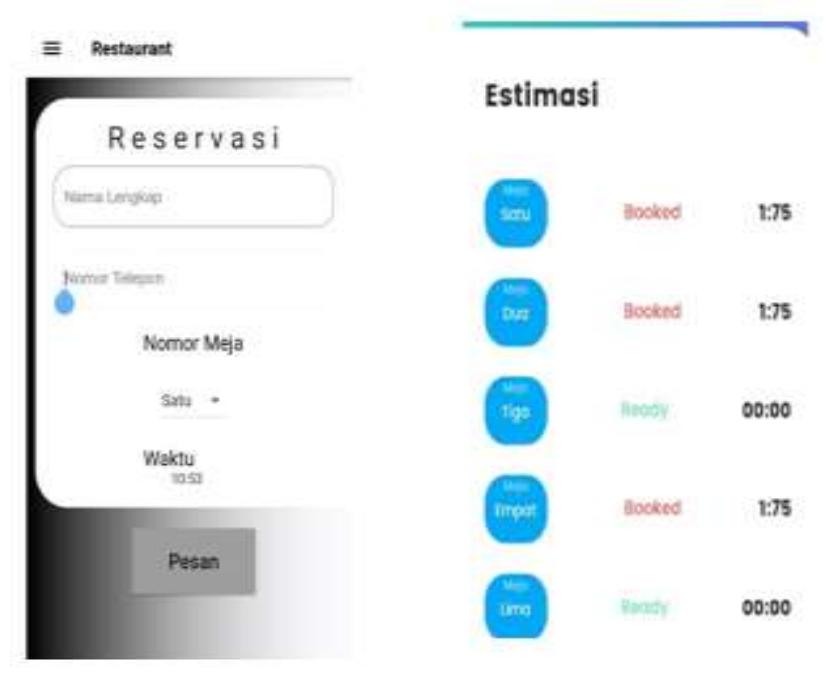

Gambar V.5 Menu Data Pelanggan \& Estimasi

\section{KESIMPULAN}

Berdasarkan implementasi dan hasil pengujian yang telah dilakukan, maka dapat disimpulkan bahwa aplikasi ini berjalan sesuai fungsi sebagaimana mestinya. Sesuai dengan keinginan para konsumen dan para pemilik restoran, maka aplikasi ini sangat menguntungkan untuk para pengusaha restoran. Aplikasi ini memberikan berbagai pelayanan sehingga dapat membantu para pelanggan dalam memesan makanan. Dalam aplikasi ini juga terdapat fitur tambahan untuk memesan tempat agar mengurangi antrian pelanggan ketika berada di lokasi restaurant tersebut.

\section{DAFTAR PUSTAKA}

Arief, M. Rudyanto. 2011. Pemrograman Web Dinamis Menggunakan PHP Dan My SQL. Yogykarta : Andi publisher.

Basuki, 2010. Membangun Web Berbasis PHP dengan Framework Codeigniter. Yogyakarta: Lokomedia.

Dewi, 2013. Perilaku Konsumen. Palembang: Penerbit Citrabooks Indonesia. 
Volume 5 Nomor. 1, April 2020

P -ISSN : 2541-1179, E-ISSN : 2581-1711

Ojs :http://journal.uin-alauddin.ac.id/index.php/instek/index

Email : instek@uin-alauddin.ac.id

Enterprise, Jubilee. 2015. Pengenalan Visual Studio 2013. Jakarta: PT Elex Media Komputindo.

Hakim, Lukmanul dan Uus Musalini. 2004. Cara Cerdas Menguasai Layout, Desain dan Aplikasi Web. Jakarta: PT Elex Media Komputindo.

Hanif, Al Fatta. 2007. Analisis dan Perancangan Sistem Informasi, Yogyakarta.

Haughee. Eric. 2013. Instant Sublime Text Starter. Birmingham: Packt Publishing Ltd.

Hermawan. 2011. Mudah Membuat Aplikasi Android. Yogyakarta: Andi Offset.

Hidayatullah, Priyanto \& Kawistara Jauhari K. 2015. Pemrograman Web. Bandung: Informatika Bandung.

Ninemeier dan Hayes. 2006. Restaurants Operations Management Principles and Practices. Pearson.

Prasetia, Afrizal. 2017. Aplikasi Berbagi Kontak Menggunakan QR Code untuk Smartphone Android. Teknik Informatika, Fakultas Teknik. Universitas PGRI Yogyakarta.

Pressman. 2008. Software Engineering: a Practitioner's Approach Seventh Edition. New York: McGrawHill.

Ramadhan, Andresta. 2008. Pembangunan Framework Sederhana untuk Aplikasi Sistem Informasi Sekolah. Diakses tanggal 1 September 2009.

Rosa dan M. Shalahuddin. 2015. Rekayasa Perangkat Lunak Terstruktur dan Berorientasi Objek. Bandung: Informatika. 